Pfliigers Arch (1993) 425:90-99

\title{
Activation of ion transport by combined effects of ionomycin, forskolin and phorbol ester on cultured HT-29cl.19A human colonocytes
}

\author{
R. B. Bajnath ${ }^{1}$, N. van den Berghe ${ }^{2}$, H. R. De Jonge ${ }^{2}$, J. A. Groot ${ }^{1}$ \\ ${ }^{1}$ Department of Experimental Zoology, University of Amsterdam, Kruislaan 320, NL-1098 SM Amsterdam, The Netherlands \\ ${ }^{2}$ Department of Biochemistry, Erasmus University, NL-Rotterdam, The Netherlands
}

Received October 19, 1992/Received after revision April 19, 1993/Accepted June 7, 1993

\begin{abstract}
The differentiated clone 19A of the HT-29 human colon carcinoma cell line was used as a model to study the intracellular electrophysiological effects of interaction of the cAMP, the protein kinase $\mathrm{C}(\mathrm{PKC})$ and the $\mathrm{Ca}^{2+}$ pathways. (a) A synergistic effect between ionomycin and forskolin was observed. From intracellular responses it was concluded that the synergistic effect is caused by activation of an apical $\mathrm{Cl}^{-}$conductance by protein kinase $\mathrm{A}$ and a basolateral $\mathrm{K}^{+}$conductance by $\mathrm{Ca}^{2+}$. (b) A transient synergistic effect of ionomycin and the phorbol ester phorbol dibutyrate (PDB) was found. The decrease of the response appeared to be due to PKCdependent inactivation of the basolateral $\mathrm{K}^{+}$conductance. The synergism is caused by PKC-dependent increase of the apical $\mathrm{Cl}^{-}$conductance and $\mathrm{Ca}^{2+}$-dependent increase of the basolateral $\mathrm{K}^{+}$conductance. (c) The effects of carbachol and PDB were not fully additive presumably because of their convergence on PKC activation. (d) Forskolin and PDB, when added in this order, had a less than additive effect. Results of cell-attached patch-clamp studies, presented in the accompanying paper, showed a synergistic effect of forskolin and PDB on non-rectifying small-conductance $\mathrm{Cl}^{-}$channels. Assuming that these channels are involved in the transepithelial responses it is suggested that forskolin and PDB induce a modulatory, synergistic increase of the apical $\mathrm{Cl}^{-}$conductance when both pathways are activated simultaneously. (e) The HT-29cl.19A cells differ from $\mathrm{T}_{84}$ cells in that the latter did not respond with an increase of the short-circuit current to addition of phorbol ester. This may be due to a very low expression of PKC $\alpha$.
\end{abstract}

Key words: Forskolin - Carbachol - Ionomycin $\mathrm{PDB}$ - Protein kinase $\mathrm{C}-\mathrm{Cl}^{-}$channels $-\mathrm{K}^{+}$channels - Intestinal secretion - Cystic fibrosis $-\mathrm{T}_{84}$ cell line

Correspondence to: J. A. Groot

\section{Introduction}

The clone 19A of the human colon carcinoma cell line HT-29 consists of homogeneous, permanently differentiated intestinal epithelial cells, which can be grown to confluence on permeable filters and then show many features associated with $\mathrm{Cl}^{-}$-secretory epithelia $[2,3]$. These cells can be studied with conventional microelectrode techniques, so that in combination with transepithelial measurements the location of changes in potential and conductance can be deduced $[4,5,7]$.

An important aim of studying the regulation of $\mathrm{Cl}^{-}$ secretion in intestinal epithelium by neurotransmitters and hormones is to understand their mutual interactions. A difficulty is that, because of the complexity of the experimental models, it is usually not possible to discriminate between direct effects and effects caused by the production of secondary mediators in the lamina propria. The HT-29cl.19A cells can be used as a model to study the possible interaction of stimulation of $\mathrm{Cl}^{-}$secretion by different intracellular pathways. We report here the effect of addition of ionomycin followed by forskolin and of these two secretagogues in the reversed order. The effect of application of forskolin followed by ionomycin was compared with the effect of phorbol 12,13-dibutyrate (PDB) followed by ionomycin in order to emphasize the difference between protein kinase $A$ (PKA) and protein kinase $\mathrm{C}$ (PKC) activation. Because the effect of ionomycin is partially similar to the effect of carbachol it was of interest to compare effects of PDB followed by ionomycin with PDB followed by carbachol. Further, we studied the effect of forskolin followed by PDB to find possible interactions of stimulation of the PKA and PKC pathways. Finally we investigated a probable cause for the differing susceptibility of HT$29 \mathrm{cl} .19$ cells and $\mathrm{T}_{84}$ cells to activation with phorbol esters.

The results suggest the following. (a) The synergistic effect of ionomycin plus forskolin or PDB on changes in 
transepithelial potential and the equivalent short-circuit current can be explained by activation of $\mathrm{Cl}^{-}$conductance in the apical membrane by forskolin or PDB, and $\mathrm{K}^{+}$conductance in the basolateral membrane by ionomycin. The latter led to a decrease of the resistance of the basolateral membrane to $35 \%$ of its initial value. (b) The increase of intracellular $\mathrm{Ca}^{2+}$ by ionomycin may further activate the PDB-dependent pathway. (c) PDB and carbachol may act on the same pool of PKC. (d) The activation of the PKC pathway by PDB modulates the PKA-activated $\mathrm{Cl}^{-}$conductance and suggests that the PKA and PKC pathways can converge on the same type of $\mathrm{Cl}^{-}$channel. This is supported by the results of single-channel studies by the patch-clamp technique [8]. (e) It appears that the expression of $\mathrm{PKC} \alpha$, which may be involved in the PDB response [24], is much lower than in HT-29cl.19A cells.

\section{Materials and methods}

Cell culture and electrical measurements. Methods for growth and subculturing HT-29cl.19A cells and for the electrophysiological measurements have been previously described [4]. In short, HT$29 \mathrm{cl} .19 \mathrm{~A}$ cells (passage numbers $8-22$ ) were grown to confluence on rat-tail-collagen-coated Nuclepore PC filters, $13 \mathrm{~mm}$ in diameter (Nuclepore Corp. Pleasanton, USA). Confluent monolayers were mounted horizontally in a small Ussing-type chamber, leaving an oblong area of $0.30 \mathrm{~cm}^{2}$. The upper (apical) and lower (basolateral) compartments were continuously perfused with solutions maintained at $36^{\circ} \mathrm{C}$ and gassed with $5 \% \mathrm{CO}_{2} / 95 \% \mathrm{O}_{2}$. The transepithelial potential $\left(V_{\mathrm{r}}\right)$ was measured with Ringer/agar bridges, which were connected to $\mathrm{Ag} / \mathrm{AgCl}$ electrodes. The intracellular potential $\left(V_{\mathrm{a}}\right)$ was measured with glass microelectrodes filled with $0.5 \mathrm{~mol} / \mathrm{K} \mathrm{KCl}$ and connected to a high-input-impedance amplifier (W-P-Instruments, New Haven, Conn.). All measurements were performed under open-circuit conditions and the apical solution was used as reference for transepithelial and intracellular measurements. Transepithelial resistance $\left(R_{\mathrm{t}}\right)$ was calculated from the change in $V_{\mathrm{t}}$ induced by bipolar current pulses of $1 \mathrm{~s}$ duration $( \pm 10 \mu \mathrm{A}$ and $\pm 50 \mu \mathrm{A}$ ). Current was passed through electrodes $(\mathrm{Ag} / \mathrm{AgCl})$ that were located in the walls of the upper and lower compartments. The fractional resistance of the apical membrane $\left(f R_{\mathrm{a}}=R_{\mathrm{a}} /\left(R_{\mathrm{a}}+R_{\mathrm{b}}\right)\right.$ was calculated from the ratio of the changes in $V_{\mathrm{a}}$ and $V_{\mathrm{t}}$ induced by the current pulses. Only monolayers with transepithelial resistances above $50 \Omega \mathrm{cm}^{2}$ were used. Corrections for solution resistance and potential offset were made. The microelectrodes had tip resistances between $100 \mathrm{M} \Omega$ and $200 \mathrm{M} \Omega$ and the tip potentials were about $-2 \mathrm{mV}$. The effect of added chemicals was studied during simultaneous recordings of the intracellular potential and the transepithelial potential. The changes in potential and resistance were analysed by means of an equivalent electrical circuit for leaky epithelia [15].

Immunoblotting of PKC $\alpha$. HT-29cl.19A cells and $\mathrm{T}_{84}$ cells (passage 43) were plated at a $1: 2.5$ surface ratio on tissue-culture-treated polycarbonate filters (Transwell, Costar) and grown for different lengths of time ( $3-24$ days) as described earlier [4]. The preparation of cell lysates in sodium dodecyl sulphate sample buffer, the separation of proteins by sodium dodecyl sulphate/polyacrylamide gel electrophoresis, their transfer to nitrocellulose paper and their incubation with PKC $\alpha$-specific antiserum were performed as described in a previous paper [24].

Solutions and chemicals. All experiments were carried out with a standard Ringer solution with the following composition (in mmol/ 1): $\mathrm{NaCl} 117.5, \mathrm{KCl}$ 5.7, $\mathrm{NaHCO}_{3} 25.0, \mathrm{NaH}_{2} \mathrm{PO}_{4} 1.2, \mathrm{CaCl}_{2} 2.5$, $\mathrm{MgSO}_{4} 1.2$, glucose 27.8 ( $\mathrm{pH} 7.4$ ). Forskolin, ionomycin, PDB, and carbachol were purchased from Sigma Chemical Company, St Louis. Rainbow protein molecular mass markers were from Amersham International (UK). Rabbit polyclonal PKC $\alpha$-specific antibody was kindly donated by Dr. P. J. Parker (I. C. R. F. London). The $\mathrm{T}_{84}$ human colon carcinoma cell line was a gift from the late Dr. K. Dharmsathaphorn (University of California, San Diego, School of Medicine, USA).

All results are expressed as means \pm SEM. The Student $t$-test (paired or unpaired) was used to evaluate statistical significance. In the original recorder tracings $V_{\mathrm{t}}$ and $V_{\mathrm{a}}$ are displaced in time because the recorder pens use the full paper-width and usually the tracings cross each other. Therefore the recordings were copied and the tracing aligned in time.

\section{Glossary of symbols used}

$V_{t}, V_{\mathrm{a}}$, electrical potential difference across the monolayer and the apical cell membrane (both with the apical solution as reference) respectively, in $\mathrm{mV}$.

$E_{\mathrm{a}}, E_{\mathrm{b}}$, electromotive force across the apical and the basolateral membrane respectively, in $\mathrm{mV}$

$R_{\mathrm{t}}$, transepithelial resistance in $\Omega \mathrm{cm}^{2}$

$R_{\mathrm{a}}, R_{\mathrm{b}}, R_{\mathrm{p}}$, electrical resistance of the apical- and the basolateral cell membrane and the paracellular pathway, in $\Omega \mathrm{cm}^{2}$

$G_{\mathrm{t}}, G_{\mathrm{p}}, G_{\mathrm{c}}$, transepithelial conductance and conductance of the paracellular and the cellular pathway respectively, in $\mathrm{mS} \mathrm{cm} \mathrm{cm}^{-2}$

$G_{\mathrm{a}}, G_{\mathrm{b}}$, conductance of the apical and the basolateral membrane respectively, in $\mathrm{mS} \mathrm{cm}-2$

$\mathrm{f} R_{\mathrm{a}}, \mathrm{f} R_{\mathrm{b}}$, fractional resistance of apical and basolateral membrane, respectively $\left[\mathrm{f} R_{\mathrm{a}}=R_{\mathrm{a}} /\left(R_{\mathrm{a}}+R_{\mathrm{b}}\right), \mathrm{f} R_{\mathrm{b}}=1-\mathrm{f} R_{\mathrm{a}}\right]$.

\section{Results}

\section{Forskolin and ionomycin}

By sequentially activating the $\mathrm{Ca}^{2+}$ pathway and the cAMP pathway in this and in the reversed order we studied the possible cause for the synergistic effect on the transepithelial potential of stimulating the two pathways. Moreover, these experiments could be used to elucidate the location of the $\mathrm{Ca}^{2+}$-activated conductances. We have reported [5] that the application of ionomycin has a biphasic effect on the intracellular potential but a negligible effect on the transepithelial potential. The lack of effect on the transepithelial potential indicates that no transcellular current can flow. This may be because the conductance is increased in both membranes or because the conductance in the non-activated membrane is insufficient to carry the current. The transient depolarization during the first phase of the response to ionomycin ( $7.5 \pm 2.0 \mathrm{mV}, n=11$ ) was dependent on the presence of $\mathrm{Cl}^{-}$, indicating the activation of a $\mathrm{Cl}^{-}$conductance. The absence of a transepithelial effect in comparison with the effect of forskolin [4] suggests that the activation is not in the apical membrane, but in both membranes or only in the basolateral membrane.

Table 1 shows that the ionomycin-induced persistent hyperpolarization of $V_{\mathrm{a}}$ is accompanied by an increase $\mathrm{f} R_{\mathrm{a}}$. The decrease of $R_{\mathrm{t}}$, accompanying the increase of $\mathrm{f} R_{\mathrm{a}}$ when ionomycin was added in the presence of forskolin (see Table 2) indicates that the increase of $f R_{\mathrm{a}}$ is mainly due to a decrease of $R_{\mathrm{b}}$. An explanation for the hyperpolarization may be an increased $\mathrm{K}^{+}$conductance 
Table 1. Effect of cumulative addition of ionomycin followed by forskolin ${ }^{a}$

\begin{tabular}{llllll}
\hline Condition & $V_{\mathrm{t}}(\mathrm{mV})$ & $V_{\mathrm{a}}(\mathrm{mV})$ & $R_{\mathrm{t}}\left(\Omega \mathrm{cm}^{2}\right)$ & $\mathrm{f} R_{\mathrm{a}}$ & $\mathrm{eq} \cdot I_{\mathrm{sc}}\left(\mu \mathrm{A} / \mathrm{cm}^{2}\right)$ \\
\hline Control & $0.7 \pm 0.2$ & $-51 \pm 2$ & $127 \pm 20$ & $0.86 \pm 0.04$ & $5 \pm 2$ \\
Ionomycin & $0.8 \pm 0.3 *$ & $-60 \pm 2 * *$ & $124 \pm 22^{*}$ & $0.95 \pm 0.03 * *$ & $6 \pm 2 *$ \\
Ionomycin + forskolin & $7.7 \pm 1.5 * *$ & $-25 \pm 2 * *$ & $110 \pm 18 * *$ & $0.16 \pm 0.01 * *$ & $70 \pm 12 * *$ \\
\hline
\end{tabular}

${ }^{a}$ Values represent the mean and SEM for five experiments. The values with ionomycin were read 5 min after its addition. $I_{s c}$ was calculated from $V_{\mathrm{t}}$ and $R_{\mathrm{t}}$

* Values do not differ significantly from the values in the previous condition.

** Significantly different from previous condition $(P<0.01$, paired $t$-test)

Table 2. Effect of forskolin and ionomycin in the presence of forskolin ${ }^{2}$

\begin{tabular}{llllrr}
\hline Condition & $V_{\mathrm{t}}(\mathrm{mV})$ & $V_{\mathrm{a}}(\mathrm{mV})$ & $R_{\mathrm{t}}\left(\Omega \mathrm{cm}^{2}\right)$ & $\mathrm{f} R_{\mathrm{a}}$ & $\mathrm{eq} . I_{\mathrm{sc}}\left(\mu \mathrm{A} / \mathrm{cm}^{2}\right)$ \\
\hline Control & $1.0 \pm 0.1$ & $-48 \pm 2$ & $154 \pm 18$ & $0.86 \pm 0.02$ & $7 \pm 1$ \\
Forskolin & $5.4 \pm 0.9$ & $-18 \pm 1$ & $138 \pm 16$ & $0.12 \pm 0.02$ & $39 \pm 4$ \\
Forskolin + ionomycin & $8.1 \pm 1.8$ & $-27 \pm 3$ & $128 \pm 14$ & $0.24 \pm 0.04$ & $63 \pm 14$ \\
\hline
\end{tabular}

a Values represent the mean and SEM for ten experiments. All changes are statistically significant $(P<0.01$, paired $t$-test $)$

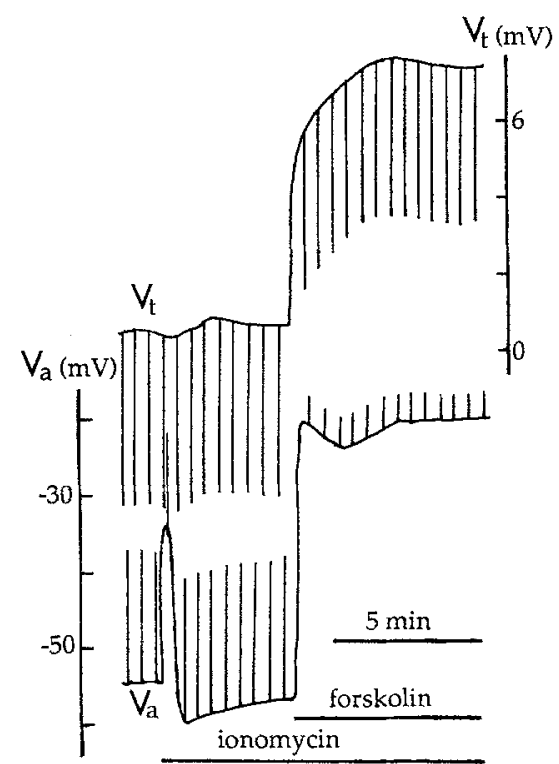

Fig. 1. Changes in intracellular potential $\left(V_{\mathrm{a}}\right)$ and of the transepithelial potential $\left(V_{t}\right)$ induced by ionomycin $(10 \mu \mathrm{M})$ followed by forskolin $(10 \mu \mathrm{M})$, as indicated by the horizontal bars. Note the negligible change in $V_{\mathrm{t}}$ after ionomycin and the large change of $V_{\mathrm{t}}$ after forskolin, which is larger than when forskolin is added alone (compare Fig. 2, Tables 1 and 2). The vertical deflections are from current pulses to calculate the resistances. The voltage excursions have been redrawn in only one direction; however, the pulses were bipolar $\left( \pm 10 \mu \mathrm{A}\right.$ for $V_{\mathrm{t}}$ and $\pm 50 \mu \mathrm{A}$ for $\left.V_{\mathrm{a}}\right)$

of the basolateral membrane. This would increase the driving force for $\mathrm{Cl}^{-}$efflux if a $\mathrm{Cl}^{-}$channel was activated. As expected from an increased basolateral $\mathrm{K}^{+}$ conductance, when forskolin was added after ionomycin (Fig. 1), the increase of $V_{\mathrm{t}}$ and the equivalent short-circuit current was larger than that without preincubation with ionomycin (compare Tables 1 and 2).

The question whether ionomycin activates $\mathrm{Cl}^{-}$and $\mathrm{K}^{+}$channels in both membranes or only in the basolateral membrane has been studied by analysing the effect

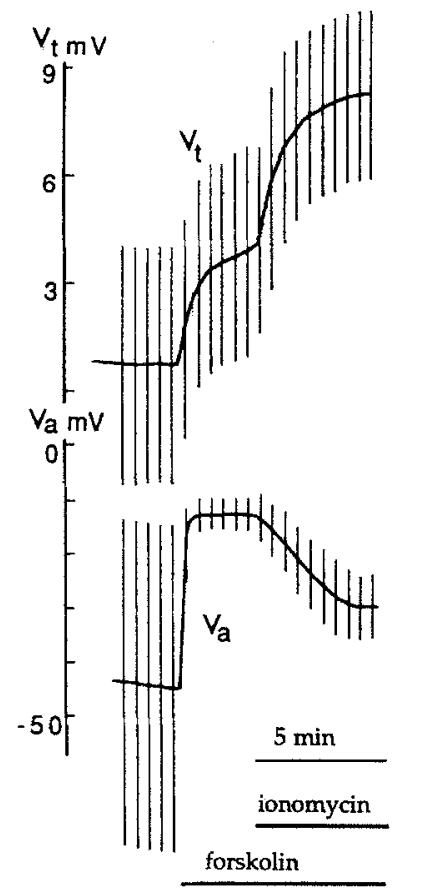

Fig. 2. Changes in potential induced by the cumulative addition of forskolin and ionomycin, as indicated by the horizontal bars (concentrations as in Fig. 1). Compare the effect of ionomycin on $V_{t}$ in this figure with the effect shown in Fig. 1. Vertical deflections are from current pulses ( $\pm 10 \mu \mathrm{A}$ for $V_{\mathrm{t}}$ and $\pm 50 \mu \mathrm{A}$ for $V_{\mathrm{a}}$ )

of addition of ionomycin after forskolin. If ionomycin, during the first phase, increased only the basolateral conductance for $\mathrm{Cl}^{-}$we would expect that the transcellular current would decrease transiently because then part of the $\mathrm{Cl}^{-}$could flow through the basolateral membrane. Figure 2 illustrates that the transepithelial potential did not show a sign of decrease but started to increase simultaneously with the hyperpolarization of $V_{\mathrm{a}}$. Therefore we conclude that ionomycin induced an increase of the $\mathrm{Cl}^{-}$ conductance in both membranes. The first phase of the 


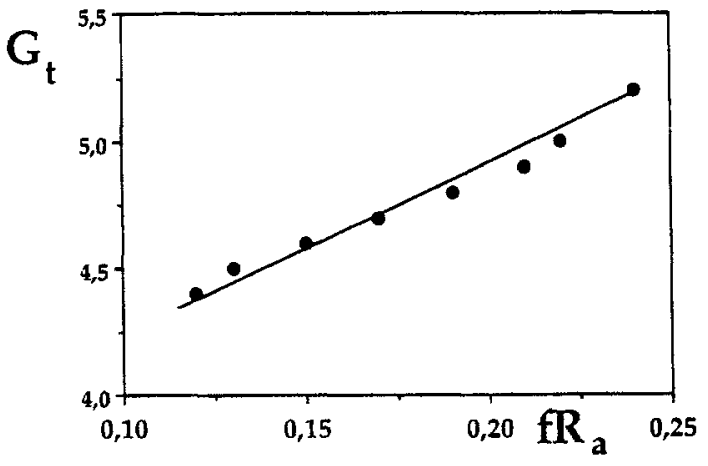

Fig. 3. Plot of $G_{\mathrm{t}}$ in $\mathrm{mS} / \mathrm{cm}^{2}$ versus $\mathrm{f} R_{\mathrm{a}}$ after addition of ionomycin in the presence of forskolin. The addition of ionomycin after forskolin induced an increase of $G_{\mathrm{t}}$ and $\mathrm{f} R_{\mathrm{a}}$. Points are taken at 30-s intervals after addition of ionomycin. The relation appears to be linear, suggesting that $G_{\mathrm{p}}$ and $G_{\mathrm{a}}\left(=1 / R_{\mathrm{a}}\right)$ remain constant under these conditions and during this period $(3.5 \mathrm{~min})$. Example of four similar experiments

ionomycin response could not be observed in the intracellular tracing. This is similar to findings with carbachol [5] and may be because forskolin already brought the potential near to the $\mathrm{Cl}^{-}$equilibrium potential [4].

Whether ionomycin increased the $\mathrm{K}^{+}$conductance in both or only the basolateral membrane was studied from the relation between $G_{\mathrm{t}}$ and $\mathrm{f} R_{\mathrm{a}}$ during activation by ionomycin in the presence of forskolin.

From equivalent circuit analyses [4], because $G_{\mathrm{t}}=$ $G_{\mathrm{p}}+G_{\mathrm{c}}$, it can be deduced that

$G_{\mathrm{t}}=G_{\mathrm{p}}+G_{\mathrm{a}} \cdot \mathrm{f} R_{\mathrm{a}}=G_{\mathrm{p}}+G_{\mathrm{b}} \cdot \mathrm{f} R_{\mathrm{b}}$.

If a secretagogue selectively alters only one of the resistive barriers of the cellular pathway a linear relation between $G_{\mathrm{t}}$ and $f R_{\mathrm{a}}$ or $\mathrm{f} R_{\mathrm{b}}$ will exist. An estimation can then be made of the conductance of the non-changing membrane and of the conductance of the paracellular resistance; e. g. if $G_{\mathrm{a}}$ and $G_{\mathrm{p}}$ are constant a plot of $G_{\mathrm{t}}$ versus $\mathrm{f} R_{\mathrm{a}}$ yields a slope of $G_{\mathrm{a}}$ and an intercept of $G_{\mathrm{p}}$. We plotted the values of $G_{\mathrm{t}}$ versus $\mathrm{f} R_{\mathrm{a}}$ at 30 -s intervals after the addition of ionomycin in the presence of forskolin. The linear relation between $G_{\mathrm{t}}$ and $f R_{\mathrm{a}}$ (Fig. 3) suggests that, under these conditions, $G_{\mathrm{p}}$ and $G_{\mathrm{a}}$ remained constant and that only $R_{\mathrm{b}}$ was decreased by ionomycin. Because this is simultaneous with a hyperpolarization, it appears that the increase in $\mathrm{f} R_{\mathrm{a}}$ induced by ionomycin (see Tables 1 and 2) can be ascribed to the activation of $\mathrm{K}^{+}$channels in the basolateral membrane.

Because from these plots $G_{\mathrm{a}}$ and $G_{\mathrm{p}}$ can be estimated, $G_{\mathrm{b}}$ can be calculated at each point. From four similar experiments the time course of the decrease of $R_{\mathrm{b}}$ was calculated. Figure 4 shows that ionomycin reduced $R_{\mathrm{b}}$ to about $35 \%$ of its original value with a halftime of $40 \mathrm{~s}$.

Table 2 shows further that, when the conductance of the apical membrane had been previously increased by activation of the PKA pathway, cumulative addition of ionomycin induced a further increase of $V_{\mathrm{t}}$ and an equivalent short-circuit current of $24 \mu \mathrm{A} / \mathrm{cm}^{2}$. This is in sharp contrast with the insignificant effect of ionomycin on the transepithelial potential when added alone.

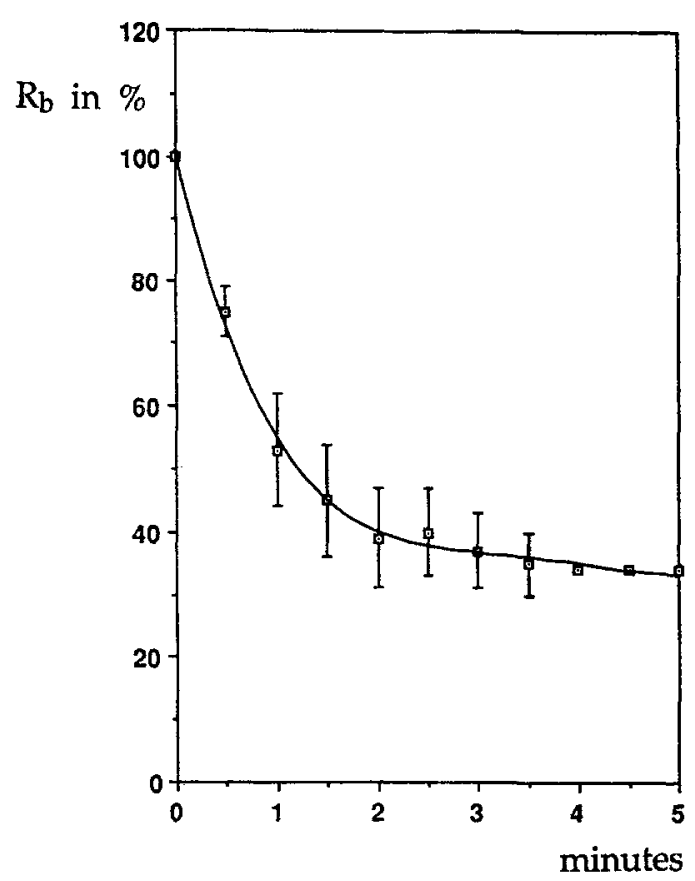

Fig. 4. Time course of the change in the basolateral membrane resistance $\left(R_{\mathrm{b}}\right)$ induced by ionomycin in the presence of forskolin. The value of $R_{\mathrm{b}}$ was calculated from $\mathrm{f} R_{\mathrm{a}}$, knowing the value of $R_{\mathrm{a}}$, which was determined from the slope of graphs as shown in Fig. 3 . The points are means \pm SEM from four experiments except for the last three points, which are from one experiment

\section{PDB followed by ionomycin}

Because PDB and forskolin differ in their effects, in that PDB increases the apical $\mathrm{Cl}^{-}$conductance less efficiently and inhibits the basal and the ionomycin-induced $\mathrm{K}^{+}$conductance in the basolateral membrane [7, 23], it was of interest to compare the effect of ionomycin after PDB with its effect after forskolin. Ionomycin was added at the summit of the PDB-induced increase of $V_{t}$. Figure $5 \mathrm{~A}$ and Table 3 show the complex response of $V_{\mathrm{a}}$ and $V_{\mathrm{t}}$. As when it was added first, ionomycin induced a transient depolarization of $V_{\mathrm{a}}(6.5 \pm 2.6 \mathrm{mV})$, but this time $V_{t}$ decreased by $0.9 \pm 0.3 \mathrm{mV}(n=8)$. The ensuing increase of $V_{\mathrm{t}}$ appeared to coincide with the repolarization of $V_{\mathrm{a}}$ and increase of $\mathrm{f} R_{\mathrm{a}}$. From the time course of the following depolarization of $V_{\mathrm{a}}$ and changes in $V_{\mathrm{t}}$ one can conclude that the depolarization of $V_{\mathrm{a}}$ must be caused by depolarization of $E_{\mathrm{a}}$ and a slower depolarization of $E_{\mathrm{b}}$. The depolarization of $E_{\mathrm{a}}$ suggests that the high $\mathrm{Ca}^{2+}$ concentration may induce a further activation of PKC or a further increase of the PKC-activated $\mathrm{Cl}^{-}$ conductance. The depolarization of $E_{\mathrm{b}}$ and concomitant decrease of $V_{\mathrm{t}}$ was anticipated from the already known inhibitory effect of PDB on ionomycin-activated $\mathrm{K}^{+}$ conductance [7].

\section{PDB followed by carbachol}

Table 4 and Fig. $5 \mathrm{~B}$ show the effect of pre-incubation with PDB on the carbachol response. Carbachol was added at the top of the PDB-induced response of $V_{t}$. Like 
Table 3. Effect of phorbol dibutyrate (PDB) and of ionomycin in the presence of PDB ${ }^{\text {a }}$

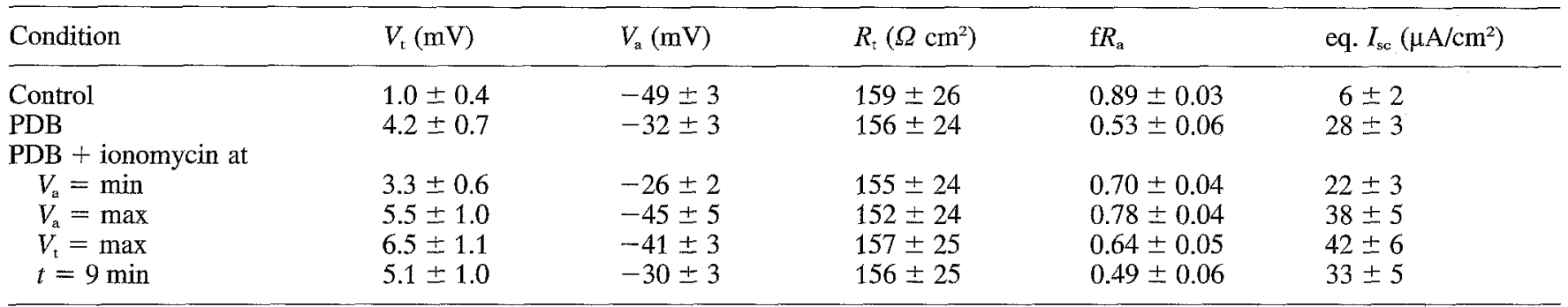

a Values represent the mean and SEM for eight monolayers. Ionomycin $(1 \mu \mathrm{M})$ was added to the apical perfusate at the peak of the change in $V_{\mathrm{t}}$ induced by PDB $(1 \mu \mathrm{M})$, reached at $6 \pm 0.3 \mathrm{~min}$. The values are those after addition of ionomycin at the top of the ionomycininduced depolarization $\left(V_{\mathrm{a}}=\mathrm{min}\right)$, at the top of the ionomycin-induced hyperpolarization $\left(V_{\mathrm{a}}=\max \right)$, at the summit of the change in $V_{\mathrm{t}}$ $\left(V_{\mathrm{t}}=\max \right)$ and $9 \pm 0.2 \mathrm{~min}$ after addition of ionomycin. All changes are statistically significant $(P<0.01$, paired $t$-test $)$ except for $\Delta R_{\mathrm{t}}$

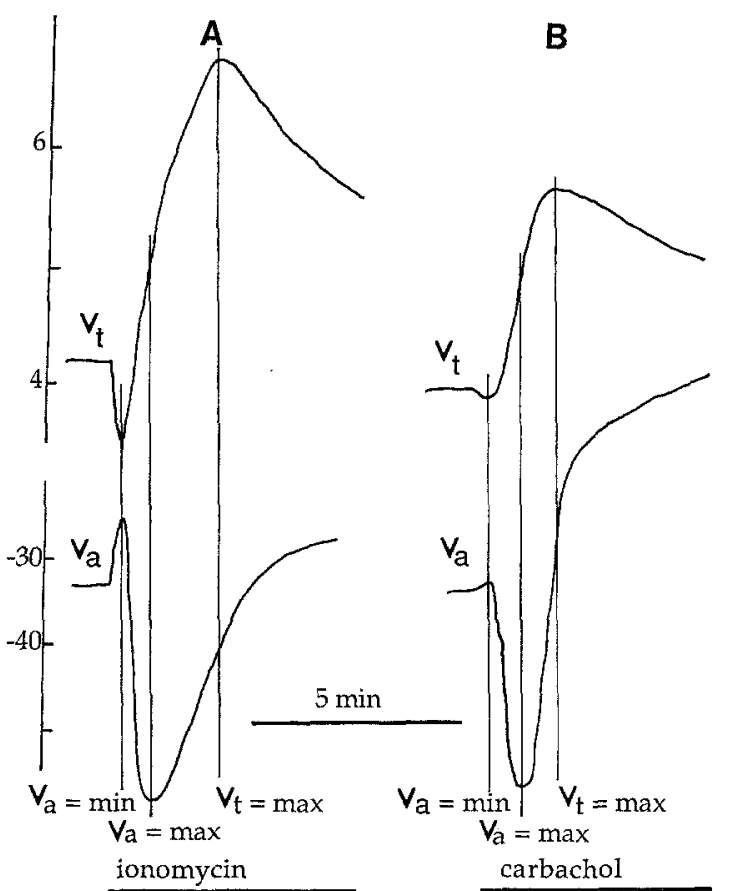

Fig. 5. A The tracings show the complex time course of the changes in $V_{\mathrm{a}}$ and $V_{\mathrm{t}}$ induced by ionomycin $(1 \mu \mathrm{M})$, added to the basolateral side at the summit of the phorbol-dibutyrate(PDB)-induced increase of $V_{\mathrm{t}}$. PDB $(1 \mu \mathrm{M})$ was applied to the apical side. The vertical lines indicate (from left to right) $V_{\mathrm{a}}=\min , V_{\mathrm{a}}=\max$ and $V_{\mathrm{t}}=\max$. Mean values at these times are given in Table 3 . The decrease of $V_{\mathrm{z}}$ and concomitant depolarization of $V_{\mathrm{a}}$ is followed by an increase of $V_{\mathrm{t}}$ and $V_{\mathrm{a}}$ but note that at the maximum of $V_{\mathrm{a}}$ the tracing of $V_{\mathrm{t}}$ continues to increase while $V_{\mathrm{a}}$ is again depolarized. The ensuing decrease of $V_{\mathrm{t}}$ occurs while $V_{\mathrm{a}}$ is still depolarizing. Voltage deflections induced by current injection were left out. B Tracings of an experiment showing the changes in $V_{t}$ and $V_{\mathrm{a}}$ induced by carbachol $(0.1 \mathrm{mM}$ basolateral side $)$ added after PDB ( $1 \mu \mathrm{M}$, apical side). Table 4 gives the means at the times indicated by the vertical lines

ionomycin, carbachol induced a small depolarization of $V_{\mathrm{a}}$ concomitant with a negative deflection of $V_{\mathrm{t}}$, which in the case of carbachol was much smaller than with ionomycin. The subsequent changes of $V_{\mathrm{t}}$ and $V_{\mathrm{a}}$ were similar to the changes induced by ionomycin. Thus, carbachol also appeared to activate PKC or PKC activated channels further and PDB also inactivated the carbacholstimulated basolateral $\mathrm{K}^{+}$conductance.

\section{$P D B$ after forskolin}

From results of earlier experiments it can be predicted that exposure of the HT-29cl.19A cells to phorbol ester and forskolin would have different effects depending on the order of addition. We showed [7] that forskolin, when added after PDB, induced a small and transient increase of $V_{\mathrm{t}}$ although $V_{\mathrm{a}}$ and $\mathrm{f} R_{\mathrm{a}}$ decreased further. The transient nature was due to the inactivation of the basolateral $\mathrm{K}^{+}$conductance by activated PKC. Thus, the cumulative effect of activation of the PKC pathway by PDB after forskolin should have a larger effect on $V_{t}$ than when forskolin is added after PDB. Figure 6 and Table 5 show the effect of the consecutive addition of PDB after a supramaximal dose of forskolin $(0.1 \mathrm{mM})$. PDB further increased the equivalent short-circuit current by $42 \%$ but did not change $V_{\mathrm{a}}$ and had only a small effect on $\mathrm{f} R_{\mathrm{a}}\left(\mathrm{f} R_{\mathrm{a}}\right.$ decreased by $\left.0.024 \pm 0.005\right)$. The increase of $V_{\mathrm{t}}$ was transient. During the decrease of $V_{\mathrm{t}}$, a further decrease of $V_{\mathrm{a}}$ and $\mathrm{f} R_{\mathrm{a}}$ was observed, illustrating the inactivation of the basolateral $\mathrm{K}^{+}$conductance by PDB. It took about 12 min to bring $V_{\mathrm{t}}$ back to the pre-PDB value. The decrease continued slowly, following the same time course as the decline in $V_{\mathrm{t}}$ after PDB alone [7].

The interesting observation in these experiments is the increase of $V_{\mathrm{t}}$ accompanied by a small but statistically significant decrease of $f R_{\mathrm{a}}$ while $V_{\mathrm{a}}$ remained constant. From the Goldman, Hodgkin and Katz equation it can be argued that if the apical $\mathrm{Cl}^{-}$permeability was further increased by PKC, this would hardly be visible as a change in $V_{a}$ because the permeability is already very high owing to the PKA-activated $\mathrm{Cl}^{-}$conductance. However, if $V_{\mathrm{a}}$ is moved away from $E_{\mathrm{Cl}}$ artificially, a further increase of the apical $\mathrm{Cl}^{-}$conductance might be revealed by a depolarization of $V_{\mathrm{a}}$. We displaced $V_{\mathrm{a}}$ by addition of ionomycin after forskolin and added PDB on top of forskolin and ionomycin. As shown in Fig. 7 and Table $5 \mathrm{~B}, \mathrm{PDB}$ induced a depolarization of $V_{\mathrm{a}}$, a decrease of $\mathrm{f} R_{\mathrm{a}}$ and a transient increase of $V_{\mathrm{t}}$. This corroborates the idea that PDB can increase the apical $\mathrm{Cl}^{--}$conductance even after pre-stimulation with a supramaximal concentration of forskolin.

We have shown that during the first $20 \mathrm{~s}$ after addition of forskolin, $G_{\mathrm{a}}$ is the only changing conductance in the equivalent circuit, $G_{\mathrm{p}}$ and $G_{\mathrm{b}}$ remain constant [4]. 
Table 4. Effect of PDB and of carbachol in the presence of PDB ${ }^{a}$

\begin{tabular}{|c|c|c|c|c|c|}
\hline Condition & $V_{\mathrm{t}}(\mathrm{mV})$ & $V_{\mathrm{a}}(\mathrm{mV})$ & $R_{\mathrm{t}}\left(\Omega \mathrm{cm}^{2}\right)$ & $\mathrm{f} R_{\mathrm{a}}$ & eq. $I_{\mathrm{sc}}\left(\mu \mathrm{A} / \mathrm{cm}^{2}\right)$ \\
\hline Control & $0.5 \pm 0.2$ & $-58 \pm 3$ & $97 \pm 10$ & $0.80 \pm 0.05$ & $5 \pm 1$ \\
\hline PDB & $3.3 \pm 0.7$ & $-35 \pm 5$ & $103 \pm 10$ & $0.35 \pm 0.06$ & $32 \pm 5$ \\
\hline$V_{\mathrm{a}}=\min$ & $3.2 \pm 0.7$ & $-33 \pm 5$ & $102 \pm 10$ & $0.36 \pm 0.07$ & $31 \pm 5$ \\
\hline$V_{\mathrm{a}}=\max$ & $4.9 \pm 1.1$ & $-44 \pm 7$ & $102 \pm 10^{*}$ & $0.48 \pm 0.08$ & $48 \pm 9$ \\
\hline$V_{\mathrm{t}}=\max$ & $5.3 \pm 1.1$ & $-36 \pm 4$ & $97 \pm 10$ & $0.36 \pm 0.07$ & $55 \pm 8$ \\
\hline
\end{tabular}

alues represent the means and SEM for ten experiments. Carbachol $(0.1 \mathrm{mM})$ was added to the basolateral perfusate at the peak of the change in $V_{\mathrm{t}}$ induced by PDB $(1 \mu \mathrm{M})$, reached at $7.6 \pm 0.6 \mathrm{~min}$. The values are those after addition of carbachol at the top of the carbachol-induced depolarization $\left(V_{\mathrm{a}}=\mathrm{min}\right)$, at the top of the carbachol-induced hyperpolarization $\left(V_{\mathrm{a}}=\max \right)$, at the summit of the change in $V_{\mathrm{t}}\left(V_{\mathrm{t}}=\max \right)$ and $8 \pm 0.2 \mathrm{~min}$ after addition of carbachol. All changes are statistically significant $(P<0.01$, paired $t$-test $)$ except for the initial carbachol-induced changes (line 3 ) and the value marked *

Table 5. Effect of addition of PDB after incubation with forskolin or after forskolin plus ionomycin ${ }^{2}$

\begin{tabular}{|c|c|c|c|c|c|}
\hline Condition & $V_{\mathrm{t}}(\mathrm{mV})$ & $V_{\mathrm{a}}(\mathrm{mV})$ & $R_{\mathrm{t}}\left(\Omega \mathrm{cm}^{2}\right)$ & $\mathrm{f} R_{\mathrm{a}}$ & eq. $I_{\mathrm{sc}}\left(\mu \mathrm{A} / \mathrm{cm}^{2}\right)$ \\
\hline \multicolumn{6}{|l|}{ A } \\
\hline Control & $0.5 \pm 0.1$ & $-57 \pm 3$ & $147 \pm 23$ & $0.85 \pm 0.03$ & $3 \pm 1$ \\
\hline Forskolin & $5 \pm 1$ & $-22 \pm 3$ & $135 \pm 22$ & $0.11 \pm 0.03$ & $37 \pm 7$ \\
\hline Forskolin + PDB & $7.4 \pm 1.1$ & $-22 \pm 3 *$ & $140 \pm 21 *$ & $0.09 \pm 0.02$ & $53 \pm 8$ \\
\hline Forskolin $+\operatorname{PDB}(t=12 \mathrm{~min})$ & $4.8 \pm 1.1$ & $-20 \pm 3$ & $156 \pm 24$ & $0.08 \pm 0.02 *$ & $31 \pm 6$ \\
\hline \multicolumn{6}{|l|}{ B } \\
\hline Forskolin + ionomycin & $8.1 \pm 1.8$ & $-27 \pm 3$ & $128 \pm 14$ & $0.24 \pm 0.04$ & $63 \pm 14$ \\
\hline Forskolin + ionomycin + PDB & $9.8 \pm 1.8$ & $-23 \pm 2$ & $130 \pm 12 *$ & $0.15 \pm 0.03$ & $73 \pm 13$ \\
\hline$(t=13 \mathrm{~min})$ & $6.2 \pm 1.2$ & $-19 \pm 2$ & $147 \pm 19$ & $0.11 \pm 0.04$ & $40 \pm 5$ \\
\hline
\end{tabular}

a Values represent means \pm SEM of six experiments in $A$ and ten in $B$. The values in $B$ are derived from the same set of experiments as shown in Table 2. All changes are statistically significant $(P<0.01$, paired $t$-test) except for the changes marked *

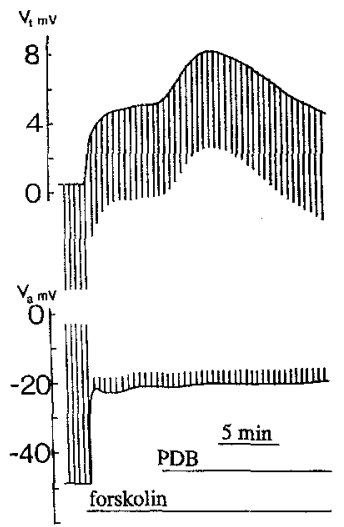

Fig. 6. Potential changes induced by cumulative addition of forskolin $(0.1 \mathrm{mM}$, basolateral side) and PDB ( $1 \mu \mathrm{M}$, apical side). Note the transient increase of $V_{\mathrm{t}}$ while $V_{\mathrm{a}}$ remains constant. Deflections of the potential were redrawn in only one direction. The current pulses used to induce these excursions were bipolar $\left( \pm 10 \mu \mathrm{A}\right.$ for $V_{\mathrm{t}}$ and $\pm 50 \mu \mathrm{A}$ for $V_{\mathrm{a}}$ )

We measured $G_{\mathrm{t}}$ and $\left(1-\mathrm{f} R_{\mathrm{a}}\right)$ at intervals of $5 \mathrm{~s}$ after the addition of forskolin (see [4]), and from a plot of $G_{\mathrm{t}}$ versus $\left(1-\mathrm{f} R_{\mathrm{a}}\right)$ after forskolin and after PDB plus forskolin the values of $G_{\mathrm{p}}$ and $G_{\mathrm{b}}$ can be found, so that the values of $R_{\mathrm{a}}$ before and after forskolin can be calculated. Table 6 shows the values of $R_{\mathrm{a}}$ after forskolin addition
Table 6. Estimates of the resistance of the apical membrane ${ }^{a}$

\begin{tabular}{lrrr} 
Condition & \multicolumn{1}{c}{$\begin{array}{l}R_{\mathrm{a}} \\
\left(\Omega \mathrm{cm}^{2}\right)\end{array}$} & $n$ & $\begin{array}{l}\Delta G_{\mathrm{a}} \\
\left(\mathrm{mS} / \mathrm{cm}^{2}\right)\end{array}$ \\
\hline 1. Control & $2774 \pm 350$ & 11 & - \\
2. Forskolin & $280 \pm 50$ & 11 & 3.2 \\
3. PDB & $820 \pm 156$ & 6 & 0.9 \\
4. PDB + forskolin & $41 \pm 12$ & 6 & 24 \\
\hline
\end{tabular}

a Resistance was calculated from the linear relation of $G_{\mathrm{t}}$ and (1$\mathrm{f} R_{\mathrm{a}}$ ) yielding a value for $G_{\mathrm{p}}$ and $G_{\mathrm{b}}$ so that $R_{\mathrm{b}}$ can be estimated at $t=0$ and $t=20 \mathrm{~s}$ after addition of forskolin without PDB (lines 1 and 2) and after incubation with PDB (lines 3 and 4). Values for $R_{\mathrm{a}}$ differ significantly from control values $(P<0.01$, paired and unpaired $t$-test). $R_{\mathrm{a}}$ in the presence of PDB is significantly larger than with forskolin (lines 3 and $2, P<0.01$, unpaired $t$-test). $R_{\mathrm{a}}$ in the presence of PDB plus forskolin (line 4) is significantly smaller than with forskolin (line $2, P<0.01$, unpaired $t$-test) or PDB alone (line $3, P<0.01$, paired $t$-test). $A G_{\mathrm{a}}$ was calculated as $1000 /$ $R_{\text {a(exp) }}-1000 / R_{\text {a(contr) }}$

$\left(R_{\text {affsk })}\right)$, after addition of PDB but before forskolin $\left(R_{\mathrm{a}(\mathrm{PDB})}\right)$ and after the combined action of PDB and forskolin. If PDB and forskolin activate parallel $\mathrm{Cl}^{-}$conductances one would expect that the value of $R_{\mathrm{a}}$ after the combined action of the drugs can be predicted by the equivalent resistance replacing $R_{\mathrm{a}(\mathrm{fsk})}$ and $R_{\mathrm{a}(\mathrm{PDB})} \mathrm{i}$. e. $210 \Omega \mathrm{cm}^{2}$. Table 6 shows that the combined activation 


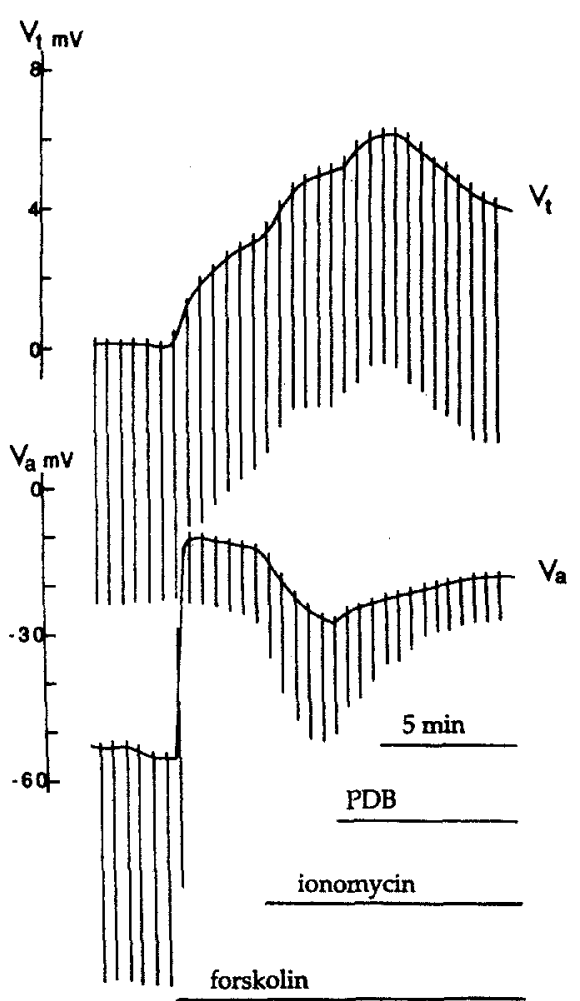

Fig. 7. Potential changes induced by cumulative addition of forskolin $(0.1 \mathrm{mM}$, basolateral side), ionomycin $(1 \mu \mathrm{M}$, basolateral side) and of PDB (1 $1 \mathrm{M}$, apical side). Note that the transient change of $V_{t}$ is now accompanied by a depolarization of $V_{\mathrm{a}}$. Current pulses were symmetrical $\left( \pm 10 \mu \mathrm{A}\right.$ for $V_{\mathrm{t}}$ and $\pm 50 \mu \mathrm{A}$ for $V_{\mathrm{a}}$ ), the voltage deflections were redrawn in only one direction

of the PKA and PKC pathways reduced $R_{\mathrm{a}}$ to a much lower value. This suggests that the PKA and PKC pathways can converge on one type of $\mathrm{Cl}^{-}$channel.

\section{Comparison of HT-29cl.19A cells and T84 cells}

An intriguing difference between the HT-29cl.19A cell line and the $\mathrm{T}_{84}$ cell line is that the latter did not respond to PDB with an increase of the transepithelial potential [26] (unpublished observations). We have explored the possibility whether this might be because an isotype of PKC, namely PKC $\alpha$ that appeared to be involved in the PDB response [24], was not expressed in $T_{84}$ cells. As shown in Fig. 8, immunoblots of homogenates of HT$29 \mathrm{cl} .19 \mathrm{~A}$ and $\mathrm{T}_{84}$ cells, taken after they had been grown for 3, 14 and 24 days, show large differences in expression of $\mathrm{PKC} \alpha$, suggesting that in the clone of $\mathrm{T}_{84}$ cells that we used, the level of expression of PKC $\alpha$ was indeed very low.

\section{Discussion}

Ionomycin induces a transient increase of the $\mathrm{Cl}$ conductance in the apical and basolateral membrane

Comparison of the initial effect of ionomycin (depolarization of $V_{a}$ ) with the effect of forskolin, which pre-

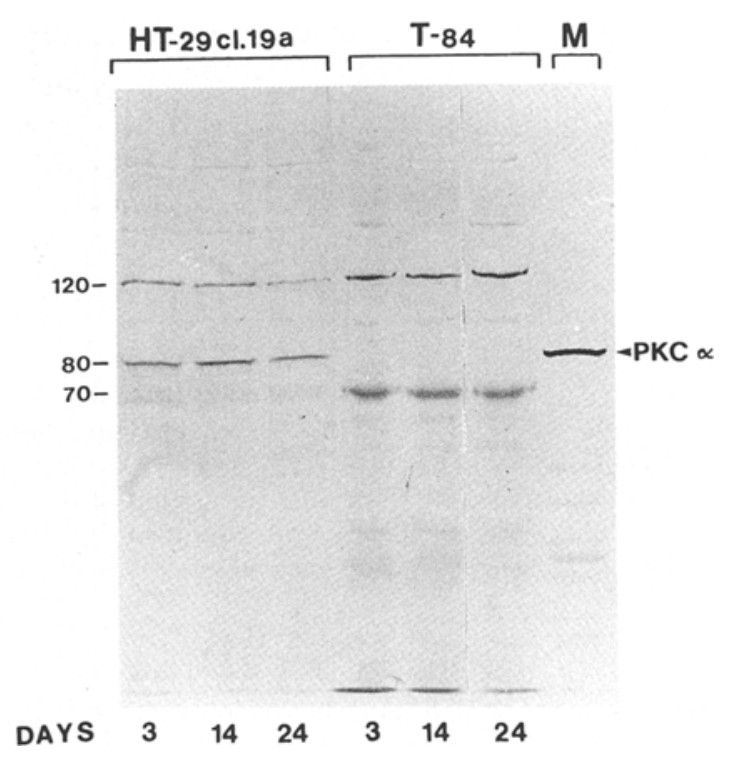

Fig. 8. Immunoblot showing different expression levels of protein kinase $\mathrm{C} \alpha(P K C \alpha)$ in HT-29cl.19A and $\mathrm{T}_{84}$ colonocytes. HT$29 \mathrm{cl} .19 \mathrm{~A}$ and $\mathrm{T}_{84}$ cells were grown for 3,14 and 24 days as described in Materials and methods. Samples of cell homogenates ( $15 \mu \mathrm{g}$ protein) were separated by SDS/PAGE, transferred to nitrocellulose paper and incubated with $\mathrm{PKC} \alpha$-specific antiserum $(1: 500)$ as described previously [24]. Lane $M$ contains a purified PKC mixture from human brain, together with Rainbow marker proteins to calibrate the molecular mass (in $\mathrm{kDa}$ ) of the major immunoreactive bands (not shown). The identification of the 80 $\mathrm{kDa}$ band as $\mathrm{PKC} \alpha$ was confirmed earlier by its blockade by the antigenic peptide and by its selective down-regulation in phorbolester-treated HT-29cl.19A cells (see [24] Fig. $3 \mathrm{~A}$ ). Immunostaining of the $70-\mathrm{kDa}$ and $120-\mathrm{kDa}$ bands was not blocked by the antigenic peptide (results not shown)

dominantly activates $\mathrm{Cl}^{-}$channels in the apical membrane, makes it less probable that ionomycin increased only the apical $\mathrm{Cl}^{-}$conductance. On the other hand, an exclusive effect of ionomycin on basolateral $\mathrm{Cl}^{-}$channels would reduce transiently the forskolin-induced serosa-to-mucosa $\mathrm{Cl}^{-}$flux and therefore the transcellular current. But this was not found when ionomycin was added after forskolin. Radioisotope efflux studies from filter-grown cells showed that the $\mathrm{Ca}^{2+}$ ionophore increased the $\mathrm{Cl}^{-}$efflux to both compartments [22]. We therefore conclude that the ionophore increased the $\mathrm{Cl}^{-}$ conductance in both membranes. But if the $\mathrm{Cl}^{-}$flux leaving the cell through the apical membrane were equal to the flux leaving the cell to the basolateral side, then, because of the polarised uptake of $\mathrm{Cl}^{-}$, a net transepithelial flux of $\mathrm{Cl}^{-}$would result, which should approximate half the basolateral uptake into the cells. As with forskolin, the $\mathrm{Cl}^{-}$efflux should be compensated by a potassium efflux through the basolateral membrane leading to a basolateral-positive potential change. Because this was not found, it is concluded that the $\mathrm{Cl}^{-}$efflux to the basolateral side must be larger than that to the apical side. This conclusion is in line with the small serosanegative deflection of $V_{\mathrm{t}}$ usually observed with carbachol or ionomycin.

We suggest that the ionophore- and carbachol-induced rapid increase of the conductance as observed in 
whole-cell patch-clamp studies in $\mathrm{T}_{84}$ and another HT29 clone $[10,14,18]$ is equivalent to the rapid depolarization in the HT-29cl.19A cells. Recently it has been shown that in $\mathrm{T}_{84}$ cells [29] and in airway cells [25] the multifunctional $\mathrm{Ca} /$ calmodulin-dependent kinase II mediates the Ca-dependent stimulation of the $\mathrm{Cl}^{-}$conductance.

The synergism between forskolin and ionomycin is based on the increase of the basolateral $\mathrm{K}^{+}$conductance

In an earlier study [4] we have shown that the cAMPinduced sustained increase of the transepithelial potential and short-circuit current was limited by the basolateral conductance. We estimated that the maximum shortcircuit current that could be carried by the basolateral efflux of $\mathrm{K}^{+}$is about $30 \mu \mathrm{A} \mathrm{cm}{ }^{-2}\left(1.1 \mu \mathrm{mol} \mathrm{cm}{ }^{-2} \mathrm{~h}^{-1}\right)$, at $R_{\mathrm{t}}=130 \Omega \mathrm{cm}^{2}$, corresponding to a $\Delta V_{\mathrm{t}}$ of about $4 \mathrm{mV}$. In the present study we showed that ionomycin, in the second phase of its effect (hyperpolarization of $V_{\mathrm{a}}$ ) can decrease the resistance of the basolateral membrane by about $65 \%$. Although the driving force for $\mathrm{K}^{+}$ efflux is simultaneously reduced by about $10 \mathrm{mV}$, this reduction will be much smaller than $65 \%$, (assuming $E_{\mathrm{K}}$ to be about $-90 \mathrm{mV}$ [18]) so that a much larger current can flow through the basolateral membrane. The $\mathrm{Ca}^{2+}$ dependent increase of the $\mathrm{K}^{+}$conductance, and the hyperpolarization induced thereby, which enlarged the driving force for $\mathrm{Cl}^{-}$efflux across the apical membrane, could well be the explanation for the observed synergism between cAMP- and $\mathrm{Ca}^{2+}$-related secretagogues on transepithelial potential and short-circuit current in monolayers of $\mathrm{T}_{84}$ cells $[9,12]$, isolated and stripped guinea-pig ileum [11], and colon [30] and MDCK cells [21].

\section{Synergism between $P D B$ and ionomycin is transient}

The response of the cells to ionomycin after incubation with PDB differed from the response after incubation with forskolin in three respects: (a) after the repolarization of $V_{\mathrm{a}}$, ionomycin induced a further depolarization of $E_{\mathrm{a}}$, which may be due to a further activation of PKC. (b) After PDB the first phase of the ionomycin effect appeared to be larger in the basolateral membrane so that a pronounced decrease of $V_{\mathrm{t}}$ could be observed. We speculate that this is due to the PDB-induced decrease of the basolateral $\mathrm{K}^{+}$conductance which makes $E_{\mathrm{b}}$ more susceptible to changes in the $\mathrm{Cl}^{-}$conductance. (c) The ionomycin-induced increase of $V_{\mathrm{t}}$ was transient after incubation with PDB. This would be the consequence of the inhibition of the ionomycin-activated basolateral $\mathrm{K}^{+}$ conductance by PDB [7].

\section{$P D B$ and carbachol have a less than additive effect}

The response to carbachol after incubation with PDB did not differ from the response to ionomycin after PDB.
However, without preincubation with PDB, their effects did differ in that the ionomycin effect lacks the thirdphase depolarization [5]. Thus, after PDB, the third phase of the carbachol response seems to be absent. This may be because PDB has already activated the pathway that is normally activated by carbachol in its third phase. In other words, we postulate that the PDB effect on the apical membrane and the third phase of the carbachol response are mediated by the same PKC pool. Support for this hypothesis comes from comparison of the effect of carbachol after forskolin and after PDB. In experiments in which carbachol was added after forskolin we found rather large effects of carbachol on the increase of $V_{\mathrm{t}}(6.0 \pm 0.6 \mathrm{mV}$ [5]). In contrast, after PDB, the response of $V_{\mathrm{t}}$ to carbachol was only $2 \mathrm{mV}$ or about $33 \%$ of its reponse after forskolin (see Table 4). The smaller effect is not primarily due to the inactivation of the basolateral $\mathrm{K}^{+}$conductance because ionomycin after PDB induced the same increase of $V_{\mathrm{t}}$ as after forskolin (see Tables 2 and 3) and carbachol itself can induce the activation of $\mathrm{Ca}^{2+}$-dependent basolateral $\mathrm{K}^{+}$conductance. Further support for the hypothesis is that recent biochemical studies showed that a particular PKC isotype, $\mathrm{PKC} \alpha$ plays a crucial role in PDB and carbachol-triggered $\mathrm{Cl}^{-}$secretion in HT-29cl.19A cells [24].

\section{Do PKA and PKC activate the same $\mathrm{Cl}^{-}$channels?}

Table $5 \mathrm{~A}$ and $\mathrm{B}$ shows that PDB in the presence of forskolin, or forskolin plus ionomycin, induced smaller increases of the short-circuit currents then when added alone $\left(22 \pm 3 \mu \mathrm{A} / \mathrm{cm}^{2}\right.$ [7]). Thus PDB plus forskolin had a less than additive effect. Among other explanations, this may be due to a rate-limiting effect of the $\mathrm{K}^{+}$conductance in the basolateral membrane (in the experiments in Table 5 A) or to metabolic constraints (in the experiments in Table $5 \mathrm{~B}$ ). Thus, the results of shortcircuit measurements can not be used to reject the possibility that the activation of $\mathrm{Cl}^{-}$channels by PKA and PKC can be additive or even synergistic.

In fact, a comparison of the conductances of the apical membrane in the presence of forskolin or PDB or PDB plus forskolin (Table 6) shows that PDB plus forskolin can induce a larger decrease of the apical resistance than expected from their individual effects. This can only be explained if the PKA and PKC pathways can converge on the same type of channels and increase their total conductance above the level reached by PKA or PKC alone. The results of patch-clamp studies presented as an abstract [6] and in the accompanying paper [8] suggest that, indeed, PKA and PKC can act synergistically on the same $\mathrm{Cl}^{-}$channel. However, our results can not exclude the possibility that PKA and PKC can also activate different parallel $\mathrm{Cl}^{-}$channels.

A schematic summary of the postulated activation and inhibition of channels is presented in Fig. 9.

\section{The relevance of studies' with cell lines}

The difficulty with the results of experiments with cell lines is that one can not be sure that the phenomena 


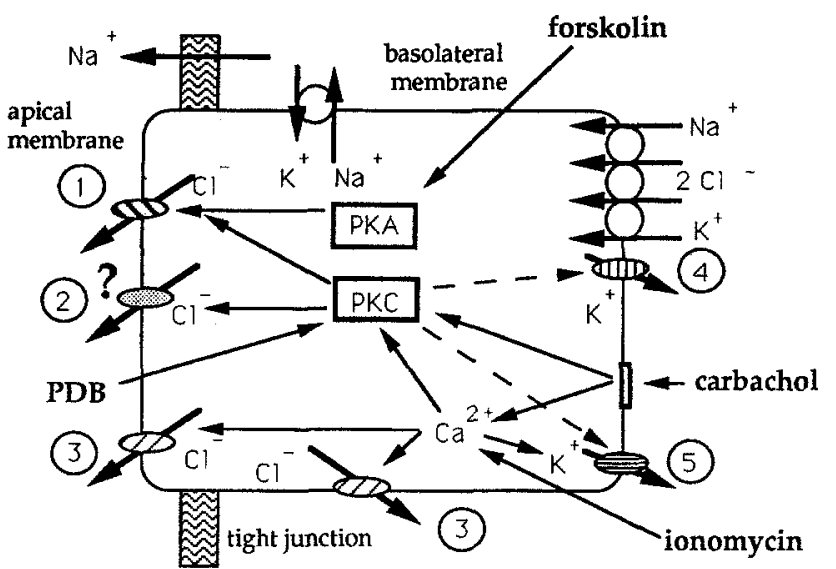

Fig. 9. Schematic summary of postulated activation and inhibition of $\mathrm{Cl}^{-}$and $\mathrm{K}^{+}$channels in HT-29cl.19A cells. Different filling of ovals indicates different types of ion channels. Thick arrows, direction of ion movement; thin and plain arrows, activation; dashed arrows, inhibition; arrow pointing to arrowhead, synergistic modulation. Numbers in circles: 1 , cAMP-dependent $\mathrm{Cl}^{-}$channel; 2 , putative $\mathrm{Cl}^{-}$channel activated by $\mathrm{PKC}$ (the presence of such a channel can not be excluded yet); $3, \mathrm{Ca}^{2+}$-dependent transient $\mathrm{Cl}$ channel; 4 , spontaneously active basal $\mathrm{K}^{+}$channel; 5 , $\mathrm{Ca}^{2+}$-dependent $\mathrm{K}^{+}$channel. $P K A$, cAMP-dependent protein kinase (cAMP being increased by direct activation of adenylyl cyclase by forskolin); $P K C$, protein kinase $C$ (activated by $\mathrm{PDB}$ or by increase of diacylglycerol, induced by carbachol). $\mathrm{Ca}^{2+}$ indicates the $\mathrm{Ca}^{2+}$ pathway, which presumably uses multifunctional $\mathrm{Ca} /$ calmodulin kinase II $[25,29]$ (activity of $\mathrm{Ca}^{2+}$ increased by the $\mathrm{Ca}^{2+}$ ionophore ionomycin or via carbachol)

occurring are of relevance for the behaviour of the original tissue. For instance, in the HT-29cl.19A cells secretion can be induced by addition of ionomycin and phorbol esters; the latter had no effect on a $\mathrm{T}_{84}$ clone that we and others [26] have used. In isolated intestine, the effects of phorbol esters and $\mathrm{Ca}^{2+}$ ionophores may be largely due to generation of arachidonic acid metabolites in the lamina propria [20], suggesting a difference between the HT-29cl.19A cell line and intestine. However, recently it has been shown that PDB could increase the short-circuit current in isolated human small intestine (but not in the colon) in the presence of inhibitors of the arachidonic-acid-degradative pathways (De Jonge et al., in preparation). The refractoriness of $\mathrm{T}_{84}$ cells to phorbol esters is not a uniform finding. For instance, recently [16] it has been shown that in $\mathrm{T}_{84}$ cells the phorbol ester, phorbol myristate acetate, had no effect on the shortcircuit current but that it could potentiate the effect of $\mathrm{Ca}^{2+}$-dependent- but not cAMP-dependent secretagogues when PMA was added $10 \mathrm{~min}$ or less before the secretagogue. This may be of relevance to the observation that the $I_{\mathrm{sc}}$ induced by $\mathrm{Ca}^{2+}$ ionophores in $\mathrm{T}_{84}$ cells is very small $[13,27,28]$ and that the ionophores have a much smaller $\Delta I_{\mathrm{sd}} \Delta \mathrm{Ca}_{\mathrm{i}}^{2+}$ ratio than carbachol. This suggests that the carbachol-induced effect in $T_{84}$ cells is triggered by other mechanisms (presumably some form of PKC) in addition to increased intracellular $\mathrm{Ca}^{2+}$. In other clones of the $\mathrm{T}_{84}$ cells, similar to the HT$29 \mathrm{cl} .19 \mathrm{~A}$ cells, phorbol esters increased the $\mathrm{Cl}^{-}$current even in the absence of $\mathrm{Ca}^{2+}$ ionophores and their effect was apparently PKC-mediated [17]. We postulate that a possible clue to the different responses to phorbol esters observed between $\mathrm{T}_{84}$ cells and HT-29cl.19A cells and probably among clones of $\mathrm{T}_{84}$ cells grown in different laboratories $[16,17,26]$ may be our observation that the expression level of PKC $\alpha$ can differ drastically between HT-29cl.19A cells and a PDB-nonresponsive $\mathrm{T}_{84}$ cell clone (Fig. 8).

The results of this study may be placed in the perspective of the recent findings on the ion-channel defect involved in the genetic disease cystic fibrosis. An interesting difference between intestine and airway epithelia is that in cystic fibrosis intestine the response to carbachol is strongly attenuated, while it is still present in airway epithelium [19]. The present study and earlier work [5] suggest that the $\mathrm{Ca}^{2+}$-activated $\mathrm{Cl}^{-}$channels in intestine can not be involved in transepithelial net $\mathrm{Cl}^{-}$ transport, and that PKC may activate the same $\mathrm{Cl}^{-}$channel as PKA, which is defective in cystic fibrosis. Thus the two intracellular pathways that are activated by carbachol can not lead to activation of the secretion of $\mathrm{Cl}^{-}$ in the cystic fibrosis intestine. In addition, recently it has been reported that the $\mathrm{Cl}^{-}$conductance in the apical membranes of nystatin-treated airway cells, but not $\mathrm{T}_{84}$ cells and HT-29cl.19A cells, can be increased by ionophores [1]. We observed, however, that the nystatin treatment, as used by these authors, inhibits the rapid depolarization of $V_{\mathrm{a}}$ by carbachol and ionomycin in the HT-29cl.19A cells (Bajnath and Groot, unpublished observations). The dissimilar susceptibility of the $\mathrm{Cl}^{-}$conductance in airway cells and intestinal cells to nystatin treatment suggests that the $\mathrm{Ca}$-dependent $\mathrm{Cl}^{-}$channels in these cells may be different.

\section{References}

1. Anderson MP, Welsh MJ (1991) Calcium and cAMP activate different chloride channels in the apical membrane of normal and cystic fibrosis epithelia. Proc Natl Acad Sci USA $88: 6003-6007$

2. Augeron C, Laboisse CL (1984) Emergence of permanently differentiated cell clones in a human colonic cancer cell line in culture after treatment with sodium butyrate. Cancer Res $44: 3961-3969$

3. Augeron C, Maoret JJ, Laboisse CL, Grasset E (1986) Permanently differentiated cell clones isolated from the human colonic adenocarcinoma cell line HT29: possible models for the study of ion transport and mucus production. In: Alvarado $\mathrm{F}$, van $\mathrm{Os} \mathrm{CH}$ (eds) Ion gradient coupled transport. Elsevier, Amsterdam, pp 363-366

4. Bajnath RB, Augeron C, Laboisse CL, Bijman J, De Jonge HR, Groot JA (1991) Electrophysiological studies of forskolin-induced changes in ion transport in the human colon carcinoma cell line HT-29cl.19A - lack of evidence for a cAMPactivated basolateral $\mathrm{K}^{+}$conductance. J Membr Biol 122: $239-250$

5. Bajnath RB, Dekker K, Vaandrager AB, De Jonge HR, Groot JA (1992) Biphasic increase of apical $\mathrm{Cl}^{-}$conductance by muscarinic stimulation of HT-29cl.19A human colon carcinoma cell line. Evidence for activation of different $\mathrm{Cl}^{-}$conductances by carbachol and forskolin. J Membr Biol 127:8194

6. Bajnath RB, Groot JA, De Jonge HR, Bijman J (1992) Interaction between forskolin and phorbol dibutyrate (PDB) on apical 
chloride conductance in the human colon carcinoma HT29cl.19A cells (abstract). Pflügers Arch 420:R 63

7. Bajnath RB, van Hoeve MH, De Jonge HR, Groot JA (1992) Regulation of apical $\mathrm{Cl}^{-}$conductance and basolateral $\mathrm{K}^{+}$conductance by phorbol esters in HT-29cl.19A cells. Am J Physiol $263: \mathrm{C} 759-\mathrm{C} 766$

8. Bajnath RB, Groot JA, Kansen M, De Jonge HR, Bijman J (1993) Synergistic activation of non-rectifying small-conductance chloride channels by forskolin and phorbol esters in cellattached patches of the human colon carcinoma cell line HT29cl.19A. Pflügers Arch 425:100-108

9. Barrett KE, Dharmsathaphorn K (1990) Mechanisms of chloride secretion in a colonic epithelial cell line. In: Lebenthal E, Duffey ME (eds) Textbook of secretory diarrhea. Raven Press, New York, pp 59-66

10. Cliff W, Frizzell RA (1990) Separate $\mathrm{Cl}^{-}$conductances activated by cAMP and $\mathrm{Ca}^{2+}$ in Cl-secreting epithelial cells. Proc Natl Acad Sci USA 87:4956-4960

11. Cooke HJ, Zafirova M, Carey HV, Walsh JH, Grider J (1987) Vasoactive intestinal polypeptide actions on the guinea pig intestinal mucosa during neural stimulation. Gastroenterology $92: 361-370$

12. Dharmsathaphorn K, Pandol SJ (1986) Mechanism of chloride secretion induced by carbachol in a colonic epithelial cell line. J Clin Invest $77: 348-354$

13. Dharmsathaphorn K, Cohn J, Beuerlein G (1989) Multiple calcium-mediated effector mechanisms regulate chloride secretory responses in $\mathrm{T}_{84}$-cells. Am J Physiol 256: C 1224C 1230

14. Greger R, Kunzelmann K (1991) Simultaneous recording of the cell membrane potential and properties of the cell-attached membrane of HT29 colon carcinoma and CF-PAC cells. Pflügers Arch 419:209-211

15. Groot JA, Bakker $\mathrm{R}(1988) \mathrm{NaCl}$ transport in the vertebrate intestine. In: Greger R (ed) Advances in comparative and environmental physiology. Springer, Berlin Heidelberg New York, pp 103-152

16. Kachintorn $U$, Vongkovit $P$, Vajanaphanich $M$, Dinh S, Barrett $\mathrm{KE}$, Dharmsathaphorn K (1992) Dual effects of a phorbol ester on calcium-dependent chloride secretion by $\mathrm{T}_{84}$ epithelial cells. Am J Physiol 262: C 15-C 22

17. Lindeman RP, Chase HS (1992) Protein kinase $\mathrm{C}$ does not participate in carbachol's secretory action in $\mathbf{T}_{84}$ cells. Am $\mathbf{J}$ Physiol 263:C 140-146

18. Morris AP, Kirk KL, Frizzell RA (1990) Simultaneous analysis of cell $\mathrm{Ca}^{2+}$ and $\mathrm{Ca}^{2+}$-stimulated chloride conductance in colonic epithelial cells (HT-29). Cell Regul 1:951-963
19. Quinton PM (1990) Cystic fibrosis: a disease in electrolyte transport. FASEB J 4:2709-2717

20. Rao MC, De Jonge HR (1990) $\mathrm{Ca}^{2+}$ and phospholipid-dependent protein kinases. In: Lebenthal E, Duffey ME (eds) Textbook of Secretory Diarrhea. Raven Press, New York, pp 209232

21. Simmons NL (1992) Acetylcholine and kinin augmentation of $\mathrm{Cl}^{-}$secretion stimulated by prostaglandin in a canine renal epithelial cell line. J Physiol (Lond) 447:1-15

22. Vaandrager $A B$, Bajnath RB, Groot JA, Bot AGM, De Jonge $\mathrm{HR}$ (1991) $\mathrm{Ca}^{2+}$ and cAMP activate different chloride efflux pathways in HT-29.cl19A colonic epithelial cell line. Am J Physiol 261: G 958-G 965

23. Vaandrager $A B$, Van den Berghe $N$, Bot AGM, De Jonge HR (1992) Phorbol esters stimulate and inhibit $\mathrm{Cl}^{-}$secretion by different mechanisms in a colonic cell line. Am J Physiol 262: G 249-G 256

24. Van den Berghe N, Vaandrager AB, Bot AGM, Parker PJ, De Jonge HR (1992) Dual role for protein kinase $\mathrm{C} \alpha$ as a regulator of ion secretion in the HT29cl.19A human colonic cell line. Biochem J 285:673-679

25. Wagner JA, Cozens AL, Schulman H, Gruenert DC, Stryer L, Gardner P (1991) Activation of chloride channels in normal and cystic fibrosis airway epithelial cells by multifunctional calcium/calmodulin-dependent protein kinase. Nature 349: $793-796$

26. Warhurst G, Higgs $N$, Lees M, Tonge A, Turnberg L (1988) Activation of protein kinase $C$ attenuates protaglandin $\mathrm{E} 2$ responses in a colonic cell line. Am J Physiol 255: G 27-G 32

27. Wong SME, Lindeman RP, Parangi S, Chase HS (1989) Role of calcium in mediating action of carbachol in $\mathrm{T}_{84}$ cells. Am J Physiol 257:C 976-C 985

28. Wong SME, Tesfaye A, Debell MC, Chase HS (1990) Carbachol increases basolateral $\mathrm{K}^{+}$conductance in $\mathbf{T}_{84}$ cells - simultaneous measurements of cell $\langle\mathrm{Ca}\rangle$ and gK explore calcium's role. J Gen Physiol 96:1271-1285

29. Worrell RT, Frizzell RA (1991) CaMKII mediates stimulation of chloride conductance by calcium in $\mathrm{T}_{84}$ cells. Am J Physiol 260: C 877-C 882

30. Yajima T, Suzuki T, Suzuki Y (1988) Synergism between calcium-mediated and cyclic AMP-mediated activation of chloride secretion in isolated guinea pig distal colon. Jpn J Physiol $38: 427-443$ 